\title{
Resource based view of the firm as a theoretical lens on the organisational consequences of quality improvement
}

\author{
Christopher R. Burton*, Jo Rycroft-Malone
}

\section{Abstract}

Evaluating the investment that healthcare organisations make in quality improvement requires knowledge of impact at multiple levels, including patient care, workforce and other organisational resources. The degree to which these resources help organisations to survive and thrive in the challenging contexts in which healthcare is designed and delivered is unknown. Investigating this question from the perspective of the Resource Based View (RBV) of the Firm may provide insights, although is not without challenge.

Keywords: Resource Based View (RBV), Evaluation, Quality Improvement

Copyright: @ 2014 by Kerman University of Medical Sciences

Citation: Burton CR, Rycroft-Malone J. Resource based view of the firm as a theoretical lens on the organisational consequences of quality improvement. Int J Health Policy Manag 2014; 3: 113-115. doi: 10.15171/ijhpm.2014.74
Article History:

Received: 7 August 2014

Accepted: 21 August 2014

ePublished: 26 August 2014

*Correspondence to:

Christopher R. Burton

Email: c.burton@bangor.ac.uk
$\mathrm{H}$ ow healthcare organisations evaluate the impact of their investment in quality improvement programmes is poorly understood. Reflecting calls to explore the application of the Resource Based View (RBV) of the Firm for healthcare productivity, innovation and performance (1), we consider RBV as a potential explanatory theory for the evaluation of healthcare quality improvement. Questions are posed about the nature of relevant resources; competing strategic contexts; and the structures of healthcare organisations for quality improvement. In addition we point to research areas that may provide fruitful lines of enquiry in uncovering the organisational consequences of quality improvement in healthcare (2).

\section{Evaluating quality improvement}

Other than the cost effectiveness of specific interventions (3), and value for money across related interventions (4), organisational approaches to the economic evaluation of healthcare improvement are limited to costs and 'return on investment' (5). Return on Investment generally assumes that there is knowledge of what resources are relevant to an improvement initiative, and the value that can be assigned to them. In addition, it provides only limited capacity to explain the role of improvement in economic performance across large and complex organisations where there may be different engagement in improvement activity across organisational units.

Quality improvement in healthcare focuses on delivering individual clinician or organisational behaviour change around different aspects of the system, including reliability, safety, efficiency and effectiveness, and the patient experience. Behaviour change is focused on closing any gaps between unreliable and reliable performance; unsafe and safe clinical practice; evidence and care provision; or between poor patient experience and perceptions of service acceptability. In closing these gaps, different quality improvement approaches are linked to different traditions, methods and tools. However, all include a mix of cognitive and practical work for clinicians, teams and health organisations. The degree to which quality improvement activities and programmes are successful will be dependent on the context in which they operate, although the nature of contextual conditions that are pre-requisites for success are poorly understood (6). In different healthcare systems, a range of policy incentives, often in the form of financial rewards (e.g. NHS Quality and Outcomes Framework for General Practice), are available which are designed to generate buy-in and momentum for quality improvement. These provide an immediate return on participation in quality improvement programmes. However ensuring that patients receive a safe, reliable and evidence-based care experience also reflects an ethical and moral dimension, with personal consequences for individual healthcare professionals (7).

The evaluation of quality improvement requires attention to be paid to aspects of related service processes and patient outcomes, and theories of change associated with both quality improvement and target clinician behaviours. Dependent on the epistemological position of the evaluation, the resource inputs, changes and consequences of improvement can be described in a logic model to drive the evaluation, as in the case of a positivist approach. Developing and applying logic models in the complex world of quality improvement brings two challenges. First, it assumes the resource consequences of quality improvement can be appropriately theorised a priori, including the range and intensity of resources that are required for change to be effected; and the range and location of resources that may be created through improvement. Second, it neglects the complexity of observable, hidden and implicit changes associated with quality improvement in the dynamic reality within healthcare. In some approaches to evaluation 
such as realist evaluation, logic models are rejected in favour of programme theory which describes the contingency in the form of contexts and mechanisms (8). These programme theories can draw on more abstract theory, including RBV, to point to the reality of 'what works, for whom, and in what circumstances'.

\section{A resource-based view}

Originating in strategic management, the RBV of the Firm theorises organisations comprise a mix of tangible and intangible resources, including physical, human and organisational capital (9). The 'imperfect distribution' of these resources across firms, or organisations within a similar market is thought to account for variation in performance, usually in terms of market share. RBV focuses on resources that have Value, Rarity, are difficult to Imitate, and are Non-substitutable (VRIN) and explain an organisation's competitive advantage relative to others (10).

RBV focuses attention on the internal resources or strengths within an organisation to manage uncertainty, rather than capitalising on the opportunities presented by the changing external environment. Addressing these opportunities depends on both the scope to invest in improvement work (11) and organisational slack, or free resources, to support learning and innovation within the organisation (12). Organisational strengths which have strategic value will include knowledge of, and learning about improvement work located within the organisation. Attention to the internal environment of organisation can be linked through theories of Dynamic Capability such as sensing, seizing and responding to opportunity (13), and Absorptive Capacity including external exploration and internal exploitation to environmental factors that shape performance (14).

Empirical evaluations of RBV have provided only mixed evidence of construct validity (15), leading to calls for its further theoretical refinement (16). Whilst the application of the RBV to healthcare has been the focus of theoretical evaluation (1), its empirical application is limited, and its use as a theoretical lens to investigate quality improvement within healthcare is untested.

\section{Application to quality improvement}

The nature of an organisation's VRIN resources around quality improvement is poorly understood. Clearly, the context dependency of much quality improvement endeavour (6) suggests there are organisational factors which may point to resources which are necessary conditions for success. Variations in the impact of quality improvement programmes across organisations would indicate that these resources are not available in equal measure across healthcare organisations, consistent with one of the explanatory mechanisms of RBV. Themes from the knowledge management, organisational learning, and more recently knowledge mobilisation literatures demonstrate the complexity of building resources around the effective use of evidence within quality improvement initiatives. For example, some of our own research into organisational collaborations as a means of closing the gap between evidence and practice point to an interesting interplay between organisational and personal histories as preconditions of success (16). In both cases, it is likely that there is a complexity to the creation of both improvement capacity and capability, again a characteristic of VRIN resources in RBV.

The presence of VRIN resources is evidently only one part of any explanatory framework around quality improvement. The ability to recognise, mobilise and exploit these resources is key, and this may present a particular challenge for health service managers. Obtaining sustained benefits from these resources also requires some capacity of a healthcare organisation to re-engineer new resources as the strategic environments in which they are operating change over time. These organisational capacities may be evident in activities which consolidate, replicate or extend resources across an organisation; learning; and the creative integration of resources. In these ways, a healthcare organisation has the potential to increase the impact of improvement capability and learning, and strategic potential. However, and within healthcare, these strategic environments comprise a complex mix of policy; public expectations; predictable and unpredictable demands; demographics; and shifts in the technical capacity of modern healthcare. It may be difficult to disentangle the different combinations of resources that are important across these different contexts.

RBV assumes a capacity for open competition between organisations within the marketplace. However, health systems operate in a tightly managed market, or no market whatsoever. RBV has principally been used to examine performance within the commercial sector, usually in terms of a firm's financial performance, or market share, relative to its competitors. However, competition can operate in other aspects of organisational performance in quasi-market contexts, including patient choice (18); quality performance (19); efficiency and value for money (20); workforce issues (21); and reputation through public reporting (22).

$\mathrm{RBV}$ focuses on one organisational unit (the firm) and the degree to which its internal resources enable it to sustain its place within an external competitive market. This highlights one of a number of critical challenges which test the transferability of RBV to quality improvement: the ways in which healthcare organisations interconnect through national, policy and networked improvement programmes. Quality improvement initiatives represented in national programmes such as the Institute for Health Improvement (US), 1000 Lives+ (Wales), Healthcare Improvement Scotland (Scotland) and NHS Improving Quality (England) include organisational collaboration as both direct and indirect mechanisms of action. Again, drawing on our research, organisational collaboration appears to be a necessary, but not sufficient prerequisite for collective action and quality improvement (17). In addition, internal uncertainty about purpose and problematic leadership may be triggers for internal competition. Finite funding for the programme itself provided challenges to sharing learning about 'what was working' within individual collaborations. Furthermore the discourse of those staff spanning organisational boundaries reflected an entrepreneurial perspective in capturing resources 
for implementation, with a sense of professional rivalry. In addition, whilst successful commercial organisations have clarity of mission and strategy around obvious financial success measures, assessment of the performance of health organisations is inherently more complex. The complexity associated with competing expectations from payers, the public and government, professional interests and the emotionally charged nature of healthcare provide many challenges to the creation of a 'single' internal organisation. In this sense, health organisations are composed of multiple internal contexts which have to engage with multiple external contexts, many of which will be in competition with each other.

Applying RBV to the evaluation of quality improvement focuses attention on the scope of resources that are necessary conditions to success. The recognised influence of context points to the potential for these resources to be imperfectly distributed; a central tenet of RBV. The complexity of change associated with the impacts of quality improvement points to the potential for VRIN resource creation. However the mechanisms through which these resources are created, and more importantly applied, warrants further investigation within the field of healthcare quality improvement (2).

\section{Ethical issues}

Not applicable.

\section{Competing interests}

Authors declare that they have no competing interests.

\section{Authors' contributions}

$\mathrm{CB}$ and JRM conceptualised and designed the document; $C B$ drafted and edited document; CB and JRM revised and edited the document; CB and JRM agreed final draft.

\section{References}

1. Crilly T, Jashapara A, Trenholm S, Peckham A, Currie G, Ferlie E. Knowledge mobilisation in healthcare organisations: Synthesising the evidence and theory using perspectives of organisational form, resource based view of the firm and critical theory. NIHR Health Services and Delivery Research programme; 2013.

2. Burton CR, Rycroft Malone J, Robert G, Willson A, Hopkins A. Investigating the organisational impacts of quality improvement: a protocol for a realist evaluation of improvement approaches drawing on the Resource Based View of the Firm. BMJ Open 2014; 4. doi: 10.1136/bmjopen-2014-005650

3. National Institute for Health and Clinical Excellence (NICE). Briefing Paper for the Methods Working Party on the Cost Effectiveness Threshold. London: NICE; 2008.

4. Health Foundation. Looking for value in hard times. London: Health Foundation; 2012.

5. National Institute for Health and Clinical Excellence (NICE). Supporting investment in public health: Review of methods for assessing cost effectiveness, cost impact and return on investment. London: NICE; 2011.

6. Health Foundation. Perspectives on context. A selection of essays considering the role of context in successful quality improvement. London: Health Foundation; 2014.

7. Bate P, Robert G. Experience-based design: from redesigning the systems around the patient to co-designing services with the patient. Qual Saf Health Care 2006; 15: 307-10. doi: 10.1136/ qshc.2005.016527

8. Pawson R, Tilley N. Realistic Evaluation. London: Sage Publications Inc; 1997.

9. Barney J. Firm resources and sustained competitive advantage. J Manage 1991; 17: 99-120. doi: 10.1177/014920639101700108

10. Barney J, Clarke D. Resource Based Theory: Creating and Sustaining Competitive Advantage. Oxford: Oxford University Press; 2007.

11. Rosner M. Economic Determinants of Organizational Innovation. Adm Sci Q 1968; 12: 614-25. doi: 10.2307/2391536

12. Bate P, Mendel P, Robert G. Organizing for Quality: the improvement journeys of leading hospitals in Europe and the United States. Oxford: Radcliffe Publishing Ltd; 2008.

13. Teece DJ. Explicating dynamic capabilities: the nature and microfoundations of (sustainable) enterprise performance. Strategic Management Journal 2007; 28: 1319-50. doi: 10.1002/ smj. 640

14. Bierly PE, Damanpour F, Santoro MD. The Application of External Knowledge: Organizational Conditions for Exploration and Exploitation. Journal of Management Studies 2009; 46 : 481-509. doi: 10.1111/j.1467-6486.2009.00829.x

15. Newbert SL. Empirical research on the resource-based view of the firm: an assessment and suggestions for future research. Strategic Management Journal 2007; 28: 121-46. doi: 10.1002/ smj.573

16. Lockett A, Thompson S, Morgenstern U. The development of the resource-based view of the firm: a critical appraisal. International Journal of Management Reviews 2009; 11: 9-28. doi: $\quad 10.1111 /$ j.1468-2370.2008.00252.x

17. Rycroft-Malone J, Wilkinson J, Burton CR, Harvey G, McCormack B, Graham I, et al. Collaborative action around implementation in Collaborations for Leadership in Applied Health Research and Care: towards a programme theory. J Health Serv Res Policy 2013; 18: 13-26. doi: 10.1177/1355819613498859

18. Propper C. Competition, incentives and the English NHS. Health Econ 2012; 21: 33-40. doi: 10.1002/hec.1804

19. Ferlie E, Ashburner L, Fitzgerald L, Pettigrew A. The New Public Management in Action. Oxford: Oxford University Press; 1996.

20. Porter ME, Teisberg EO. Redefining Healthcare: Creating Value-based Competition on Results. Boston: Harvard Business School Press; 2006.

21. McCLure ML, Poulin MA, Sovie MD, Wandelt MA. Magnet hospitals: attraction and retention of professional nurses. Kansas City: American Academy of Nurses; 1983.

22. Doran T, Roland M. Lessons from Major Initiatives to Improve Primary Care in the United Kingdom. Health Aff (Millwood) 2010; 29: 1023-9. doi: 10.1377/hlthaff.2010.0069 